\title{
Review of Jessa Lingel (2021). The Gentrification of the Internet: How to Reclaim Our Digital Freedom
}

\author{
Oakland, CA: University of California Press. 168 pp. ISBN \\ 9780520344907 (Hardcover)
}

\section{James Benedict Brown ${ }^{1}$}

Accepted: 11 December 2021 / Published online: 22 January 2022

(c) The Author(s), under exclusive licence to Springer Nature Switzerland AG 2021

Keywords Gentrification · Internet · Postdigital · Freedom · Activism · Architecture $\cdot$ Rural $\cdot$ Urban

\section{The Metaphor of (Post)Digital Gentrification}

Lingel The Gentrification of the Internet: How to Reclaim Our Digital Freedom (2021) arrived on the same day as a flyer for home broadband Internet via the mobile network. The advertisement came from the multinational telecommunications company formed when Sweden's public telephone utility was privatised in 1993. This is the same company that disconnected the copper telephone lines to my village in 2016 because they were no longer profitable. For several years, about four hundred households in the rural periphery of our municipality had no fixed access to telephony or the Internet. Free computer dongles were distributed in compensation, but they provided patchy and inconsistent connections to the $3 \mathrm{G}$ network. Five years later, the company is back to court us with a special offer: $100 \mathrm{Mb} / \mathrm{s}$ broadband for 499 crowns (ca €50) a month and installation for 'mere' 3,490 crowns (ca €350). Amortising the installation costs over three years, a basic Internet connection-one that probably couldn't support two simultaneous Zoom calls—costs almost €60 a month.

Lingel (2021: 73) reminds that in the same year that our isolated community lost its access to the fixed telephone network, 'the United Nations declared internet access to be a basic human right, as fundamental as food, water, and freedom of movement'. Yet in the USA, and almost every other country, the 'companies controlling the cost and speed of internet access have almost entirely escaped government regulation, meaning that they have been allowed to pursue profits rather than prioritize access to technologies that are increasingly central for everyday work and social life'.

James Benedict Brown

james.brown@umu.se

1 Umeå School of Architecture, Umeå University, Umeå, Sweden 
Through the recurrent themes of displacement, isolation, and commercialization, The Gentrification of the Internet (Lingel 2021) uses gentrification as a metaphor for thinking about the politics of digital technologies. It addresses not only what happens online, but the infrastructure of how we get online, and the effective monopolistic conditions that private telecommunications companies have in many places. In Chapter four, 'The Fight for Fiber', Lingel illustrates this in stark terms. In the USA, a diverse and wide market of small, locally owned and operated Internet Service Providers (ISPs) has gradually been eliminated by a small number of massive national companies. In 1998, $92 \%$ of the US population could choose from seven or more ISPs to connect to the Internet. In 2015, less than a quarter of developed areas could choose from more than two.

If there is an immediate limitation of The Gentrification of the Internet (Lingel 2021), it is that it is an American book written for American readers, despite the global implications of the subject. Lingel explains that it is outside the scope of her book to explore 'how Silicon Valley ideology does and doesn't transfer globally' (2021: 45), but I regret that decision. After all, American big tech offshores a lot of manufacturing, coding, marketing, and technical support. The consequences of Internet gentrification on cities in the Global South are as pressing, if not more so, than in the developed North.

This is not a book for scholars; Lingel writes with a clear audience of activists and Internet users in mind. To help this audience, there is a useful glossary and list of organisations and campaign groups. Again, most of these are unfortunately located in and focused on the USA.

\section{Gentrification and Culture}

An accomplished writer and a seasoned activist, Lingel acknowledges her own privilege as someone who has contributed to urban gentrification herself. In the preface, Lingel accuses her own employer, the University of Pennsylvania, of being.

much more committed to scholarly research than to the wellbeing of its neighbors. Penn is one of only two Ivy League schools that do not pay property taxes to the city and has so far resisted the call to make payments in lieu of taxes. Penn gains a lot from being in Philadelphia and should pay its fair share as a way of giving back to the city. (Lingel 2021: viii)

Lingel acknowledges that she is a contributor to the gentrification of the cities in which she, as a privileged white cis woman, has lived. She explains that trying to come to terms with my role in gentrification has helped me to be a better activist, and it's also helped me think of the internet in a new way. I've thought a lot about what it means to be a good neighbor and the ways that my presence affects the lives of the people around me.' (20)

Approaching this book as an architect and academic, who is using his economic and cultural privilege to renovate a house in an otherwise depopulating rural community, I am strongly drawn to Lingel's analogy between urban gentrification and digital 
gentrification. Lingel refers to a number of Urban Studies scholars who have written about gentrification, including Gina Perez, Sharon Zukin, and Tracey Lindeman. These scholars contribute to an understanding of gentrification that recognises the interdependency of individuals, corporations, and public actors. It is however overlooked that many scholars of gentrification, including David Cole (1987), Ley (1996, 2003), Mathews (2010), and more recently Lees et al. (2013), have identified the role of artists as agents in gentrification. Seeking low costs, artists (and architects too) tend to kickstart gentrification by occupying and beginning to improve real estate that few others want.

Since starting out as an architecture student twenty years ago, I've lost count of how many of my classmates have contributed to the gentrification of their neighbourhood (and profited) by buying a property, using their privileged education to refurbish it, and then move on. As Kerstein (1990) found in his critical study of stage models, gentrification is ultimately a chaotic process. There is no easy parallel of these first stages of urban gentrification in The Gentrification of the Internet, which tends to focus more on the role of corporations rather than individuals. Clearest and most compelling is Lingel (2021) argument about how both urban and Internet gentrification ultimately leads to (and is driven by) corporate monopolies instead of more democratically representative community organisations.

Lingel (2021: 69) asks: 'Why is Airbnb a tech company but Hilton a hotel company? ... Why is Uber a tech company but Avis a rental car company?' The book explores the consequences of these corporate tactics to avoid regulation and oversight, which is damaging for consumers and employees alike. There is still much to be explored about the damaging ways in which Zombie companies including Uber, Lyft, and (to an extent) Tesla are all fundamentally changing the way that citizens move through cities while never actually breaking even as profitable enterprises independent of subsidy or tax avoidance.

The book also addresses the complex interplay of race, gender, and class politics in the gentrification of the Internet. It critiques how the priorities of big tech are inevitably driven by the people who work in big tech, i.e. predominantly white cis men. The monocultural workplace cultures of big tech inevitably translate into the digital cultures of these products, privileging the interests of a few. The consequent prejudice is insidious: Lingel (2021: 39-40) cites the legal action taken by the US Department of Housing and Urban Development against Facebook over targeting classified adverts at specific ethnic groups, effectively leading to the ethnic discrimination of housing. There also are positive counterexamples such as Craigslist (Lingel 2021: 67): a private company with an uncharacteristic commitment against monetising user behaviour through data acquisition and targeted advertising. 


\section{Towards a Critical Understanding of Digital Infrastructure}

This book is published at a fascinating moment in our postdigital history that Postdigital Science and Education has done much to explore. ${ }^{1}$ Two years ago, few of us had ever joined a Zoom meeting. The whole humankind, and the academia in particular, has experienced a profound reorientation of our professional and personal lives in response to the Covid-19 pandemic. The consequences for the gentrification of our online and offline worlds have been significant. Ericsson, one of Sweden's largest employers, is cutting desk-space in its four hundred worldwide offices and will invite half of its global workforce to permanently work from home. Speaking to Bloomberg in November 2021, Peter Laurin, director of Managed Services at Ericsson, said that 'it became very clear during the spring of 2020, that we are never going back to the old way of working' (Lindeberg 2021). What are the consequences of these trends for digital and urban gentrification that Lingel writes about? And what are the consequences for the metaphor of gentrification that underpins the book?

Gentrification is an inherently urban concept, and the metaphor used in this fascinating book is - so far-dependent on its application to cities. But around the world, many of the individuals who previously contributed to the gentrification of urban neighbourhoods are, like me, now pioneering a strange kind of reverse gentrification. This gentrification is not reverse in the sense that urban neighbourhoods are becoming more affordable and therefore equitable; it is reverse in the sense that the urbanising processes of gentrification are now being redirected towards the rural. Writing in the Wall Street Journal, Katherine Bindley has tracked how more and more Silicon Valley employees are asking, 'Why do we even want to be here?' (2020a), and moving out of the San Francisco Bay Area to find larger and cheaper accommodation closer to national parks and ski resorts (2020b) where they can indulge their expensive hobbies.

The Gentrification of the Internet: How to Reclaim Our Digital Freedom (Lingel 2021) will linger on my bookshelf, not as a scientific survey of the corporatisation of the Internet, but as a powerfully written and compelling piece about modern-day digital activism. But how does that connect to the flyer for wireless broadband?

After the telecommunications company decided to abandon the telephone network in our community, local residents organised, wrote letters to newspapers, and petitioned their political representatives. The municipality, the county, the European Regional Development Fund, and the European Agricultural Fund agreed to cofinance an entirely new fibre optic broadband network. Made possible with Swedish and European tax revenues, the investment represented a vote of confidence in the digital future of once thriving but now declining rural communities. I rent my broadband connection from the municipality and access the Internet via a local nonprofit ISP. For around half the cost of the private telecommunications company, we get an Internet connection of between two and three times the speed. The future of

\footnotetext{
${ }^{1}$ See Postdigital Science and Education 3(2), https://link.springer.com/journal/42438/volumes-andissues/2-3. Accessed 10 December 2021.
} 
the Internet does not have to depend on monopolistic private companies, and Lingel (2021) is right to encourage a more critical view at the infrastructure that too many of us take for granted.

\section{References}

Bindley, K. (2020a). Remote Work Is Reshaping San Francisco, as Tech Workers Flee and Rents Fall. The Wall Street Journal, 14 August. https://www-wsj-com.proxy.ub.umu.se/articles/remote-workis-reshaping-san-francisco-as-tech-workers-flee-and-rents-fall-11597413602. Accessed 8 December 2021.

Bindley, K. (2020b). Tech Workers Take to the Mountains, Bringing Silicon Valley With Them. The Wall Street Journal, 1 November. https://www.wsj.com/articles/tech-workers-take-to-the-mountainsbringing-silicon-valley-with-them-11604242802. Accessed 8 December 2021.

Cole, D. B. (1987). Artists and urban redevelopment. The Geographical Review, 77(4), 391-407. https:// doi.org/10.2307/214280.

Kerstein, R. (1990). Stage models of gentrification: an examination. Urban Affairs Quarterly, 25(4), 620639. https://doi.org/10.1177/2F004208169002500406.

Lees, L., Slater, T., \& Wyly, E. (2013). Gentrification. Abingdon: Routledge.

Ley, D. (1996). The new middle class and the remaking of the central city. Oxford: Oxford University Press.

Ley, D. (2003). Artists, aestheticisation and the field of gentrification. Urban studies, 40(12), 2527-2544. https://doi.org/10.1080/0042098032000136192.

Lindeberg, R. (2021) Ericsson Wants Half of its 102,000 Staff to Work From Home. Bloomberg, 16 November. https://www.bloomberg.com/news/articles/2021-11-16/ericsson-wants-half-of-its-102000-staff-to-work-from-home. Accessed 8 December 2021.

Lingel, J. (2021). The Gentrification of the Internet: How to Reclaim Our Digital Freedom. Oakland, CA: University of California Press.

Mathews, V. (2010). Aestheticizing space: Art, gentrification and the city. Geography Compass, 4(6), 660-675. https://doi.org/10.1111/j.1749-8198.2010.00331.x.

Publisher's Note Springer Nature remains neutral with regard to jurisdictional claims in published maps and institutional affiliations. 